\title{
Effectiveness of video-teaching programme regarding the concept of thermal protection of neonates
}

\author{
Amita Sood ${ }^{1}$, Jyoti Bala ${ }^{2}$, Yogesh Kumar ${ }^{3}$ \\ ${ }^{1}$ (Child health nursing/S. V. Memorial. college of nursing, Mudhal, Amritsar, Punjab, India) \\ ${ }^{2}$ (Child health nursing/College of Nursing, Saifai, Etawah, Uttar Pradesh, India) \\ ${ }^{3}$ (Child health nursing/ M. M. College of nursing, Mullana, Ambala, Haryana, India)
}

\begin{abstract}
Newborns are predisposed to develop hypothermia more commonly during first 12 hours of life. Neonatal hypothermia at birth increases mortality as well as significant morbidity and hospitalization period. The present study was carried out with an objective to evaluate the knowledge and skills of nursing personnel regarding concept of thermal protection of neonates before and after administration of video teaching programme. Thirty nursing personnel working in the paediatric and allied units of selected hospital of Ambala, Haryana were selected. The experimental research approach with Pre-experimental: One group pre-test posttest research design was adopted. The tools used for data collection were structured knowledge questionnaire and observation check-lists on the concept of thermal protection of neonates. The mean post-test knowledge score and mean post-test skills score of nursing personnel were higher than the mean pre-test knowledge score and mean pre-test skills score respectively. There was significant positive relationship between pre-test knowledge and pre-test skills score. There was no significant association of post-test knowledge and post-test skills score with the selected variables. Therefore, the findings of the study reveal that the video-teaching programme was effective in terms of enhancing the knowledge and skills of nursing personnel regarding the concept of thermal protection of neonates.
\end{abstract}

Keywords: Knowledge, Skills, Nursing personnel, Thermal protection, Neonates.

\section{Introduction}

Newborns are predisposed to develop hypothermia which is more common during first 12 hours of life. ${ }^{[1]}$ Hypothermia is an important determinant of the survival of newborns, especially among low-birth-weight (LBW) babies. ${ }^{[2]}$ Neonatal hypothermia is widely recognized as an important contributing factor for neonatal morbidity especially in low and middle income countries ${ }^{[3,4]}$ and has been associated with mortality risk in newborns. ${ }^{[5]}$

Newborn deaths dropped from 4.6 million in 1990 to 3.3 million in 2009, a new report by the World Health Organization. Save the Children and the London School of Hygiene and Tropical Medicine shows that the burden is far higher in the developing world, where 99 percent of newborn deaths occur. Half of the 3.3 million deaths in 2009 were in just five countries - India, Nigeria, Pakistan, China and Democratic Republic of the Congo - in part because of their very large populations. ${ }^{[6]}$

It is estimated that almost $99 \%$ of the world's neonatal deaths occur primarily in South Asia and SubSaharan Africa. In the SEAR-India, Nepal, Bangladesh, Myanmar and Indonesia contribute to $99 \%$ of the total neonatal deaths. Out of these, India has a $76.6 \%$ contribution to the regional burden of neonatal deaths. Figure 1 shows the number of neonatal and early neonatal deaths in SEAR countries and the proportion of deaths in individual countries in 2007. ${ }^{[7]}$

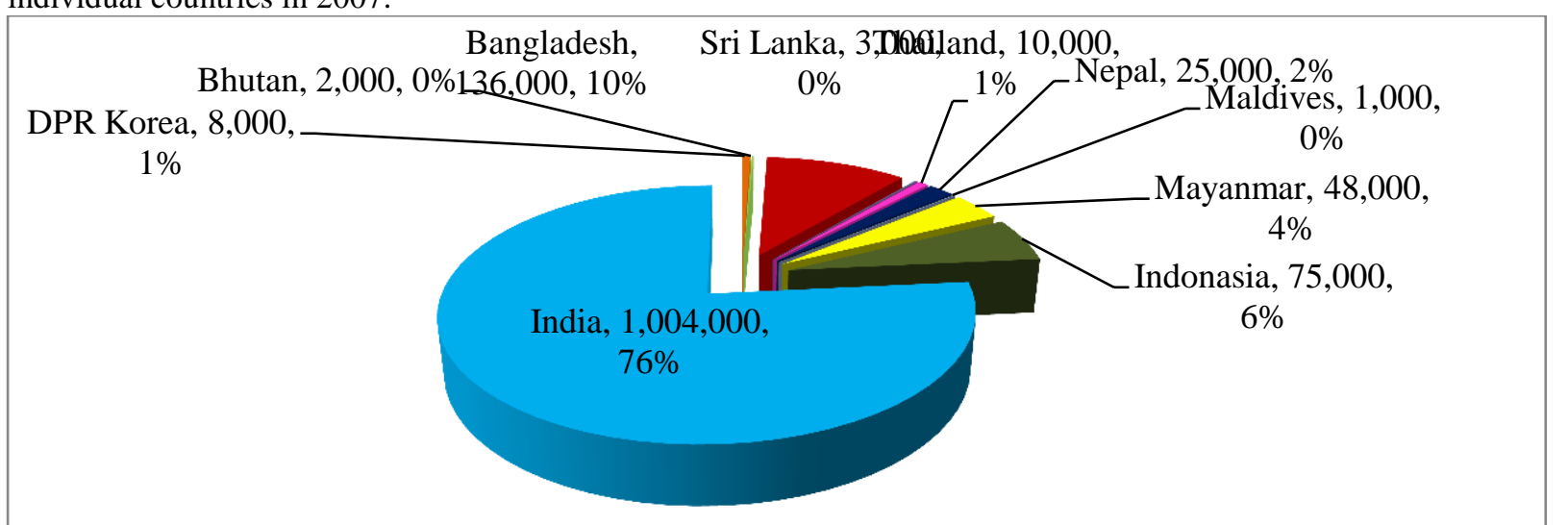

Figure 1: Pie chart showing the number of neonatal and early neonatal deaths in SEAR countries and the proportion of deaths in individual countries (2007). 
According to the Family Welfare Statistics in India 2011, in the year 2009 the infant mortality rate was 50 per 1000 live births and neonatal mortality rate was 34 per 1000 live births. The infant mortality rate of Haryana was 51 per 1000 live births and neonatal mortality rate was 35 per 1000 live births. Figure 2 shows the infant mortality rate in rural, urban and all India. ${ }^{[8]}$

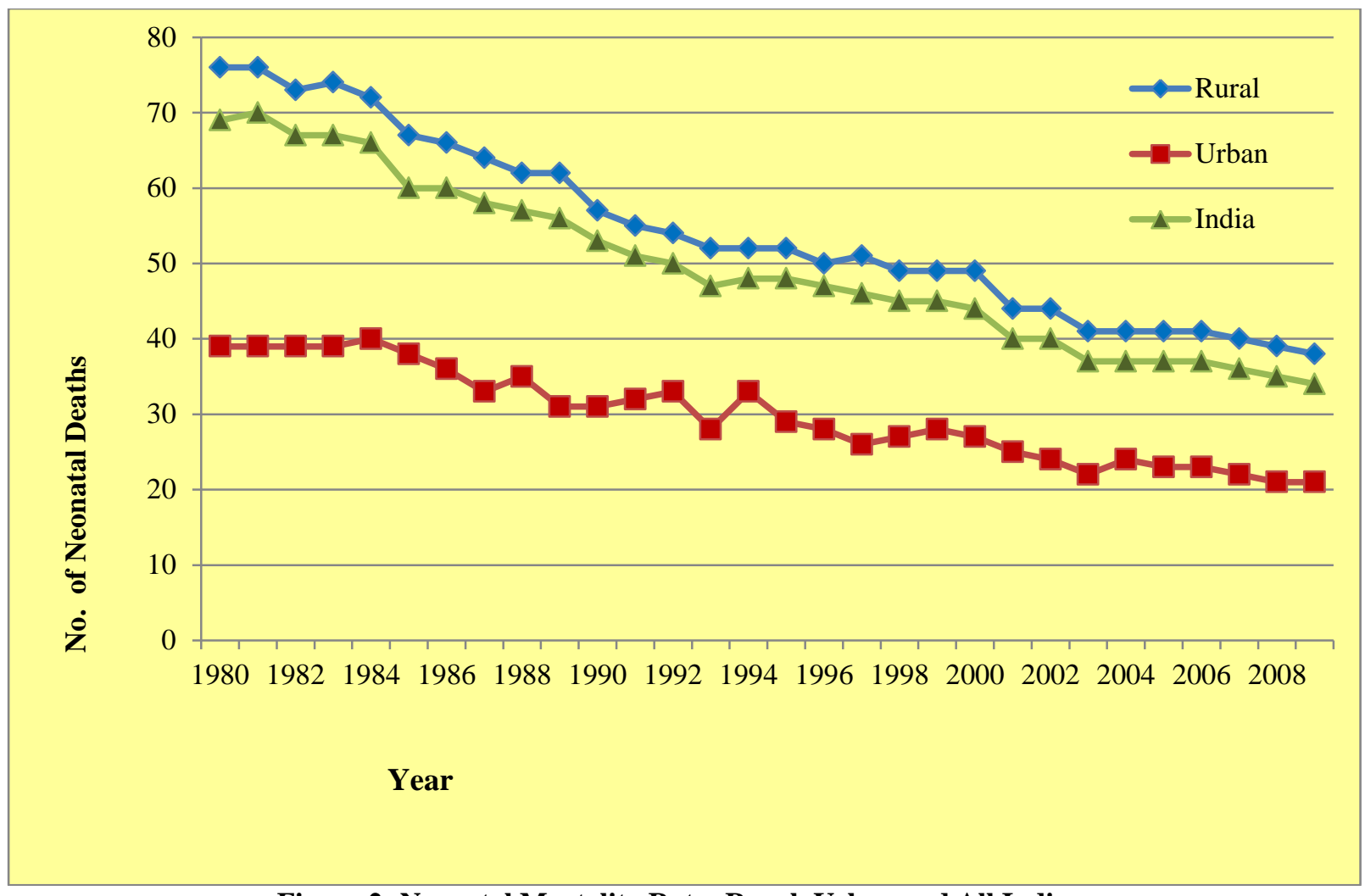

Figure 2: Neonatal Mortality Rate- Rural, Urban and All India

A study conducted to identify the incidence and the risk factors of neonatal hypothermia at referral hospitals has shown that more than $50 \%$ neonates become hypothermic soon after birth. This is one of the most serious health problems which contribute to a 3 fold higher morbidity and mortality ${ }^{[9]}$

\section{Methodology}

Present study used the experimental research approach with Pre-experimental: One group pre-test posttest research design. The setting of present study was the MMIMSR \& Hospital, Mullana, Ambala, Haryana. Thirty nursing personnel were selected from paediatric and allied units by total enumeration sampling technique. The criterion for the selection of the sample subjects was:

$\checkmark$ Nursing personnel willing to participate in the study and available at the time of data collection.

$\checkmark$ Nursing personnel having at least three months experience in paediatric and allied units of selected hospital.

$\checkmark$ Nursing personnel able to understand English.

The tools used for the study were structured knowledge questionnaire developed to assess the knowledge and observational checklist developed to assess the skills of nursing personnel regarding the concept of thermal protection of neonates.

The paper - pencil technique and observation by objective structured clinical examination (OSCE) technique with three stations in simulated setting were selected to collect data related to knowledge and skills of nursing personnel respectively.

The structured knowledge questionnaire comprised of two sections: Section-I comprised of items seeking information pertaining to the selected variables and section-II comprised of 55 knowledge items. The checklist comprised of the following three sections:Section I- Assessment of temperature, Section II- Kangaroo Mother Care \& Section III- Mechanism of heat gain or heat loss having 15, 16 \& 6 items respectively. The reliability of structured knowledge questionnaire was established by $\mathrm{KR}_{20} \&$ found out to be 0.75 and observation check-lists was established by Inter-rater reliability method \& found out to be 0.89 . 
Ethical approval was taken from the Institutional Ethical Committee of M.M. University, Mullana, Ambala. Written informed consent was obtained from the study subjects regarding their willingness to participate in the research project.

Pre-test was taken on day one and video-teaching was administered after that on the same day. Post-test was administered on day 15-16 after administration of video-teaching programme.

\section{Results}

The data presented in table 1 shows the frequency and percentage of characteristics of the nursing personnel. Majority of nursing personnel (90\%) were in the age group 20-25 years. All the nursing personnel were female. Majority of nursing personnel (90\%) were unmarried. Majority of the nursing personnel $(93.33 \%)$ had professional qualification of GNM. Out of 30 nursing personnel, majority of the nursing personnel $(76.67 \%)$ and $(86.66 \%)$ had 3 month to 1 year of experience as overall experience and experience in paediatric and allied units respectively. Majority of the nursing personnel $(93.33 \%)$ had not undergone any in-service education programme.

TABLE 1

Frequency and Percentage Distribution of Characteristics of Nursing Personnel

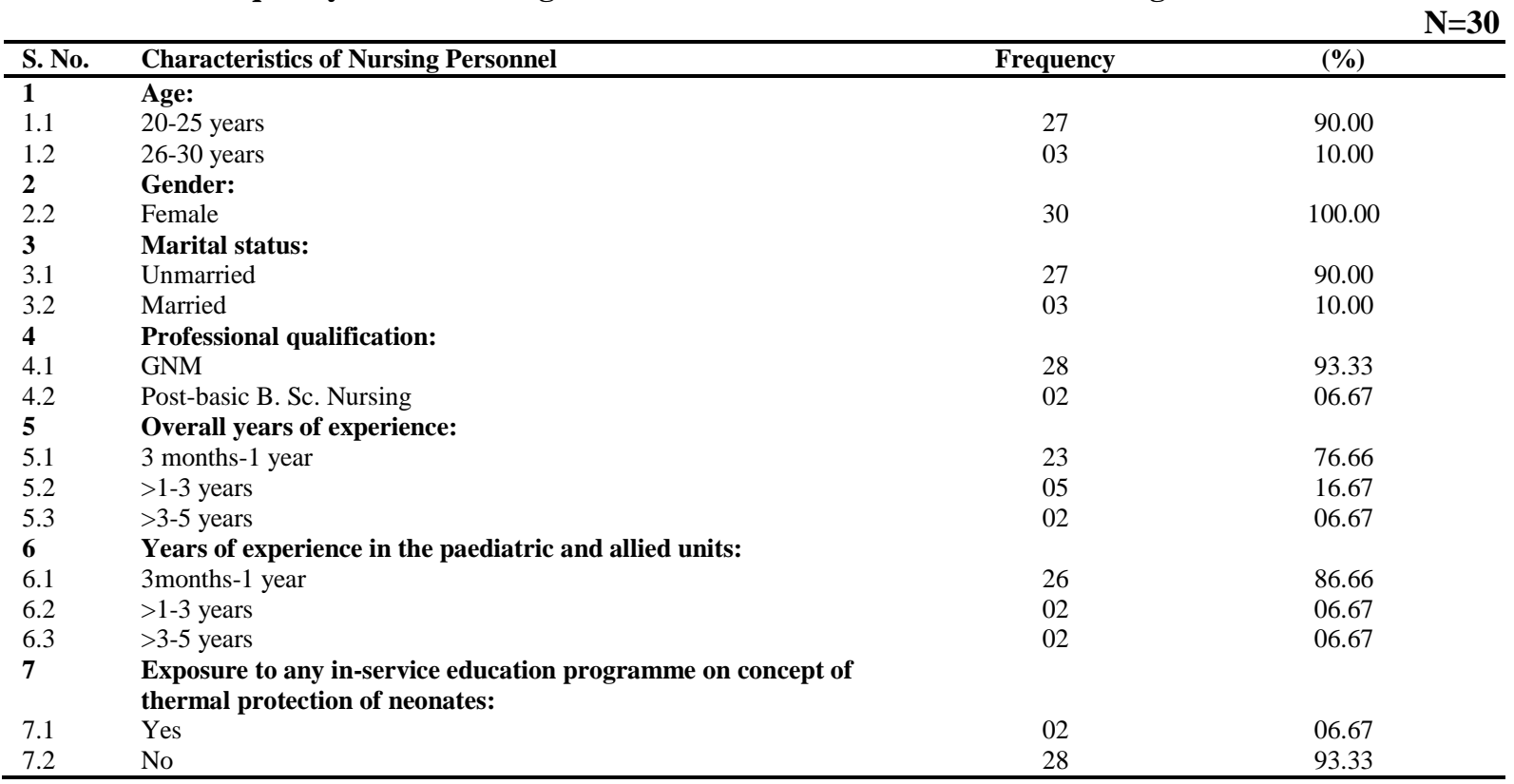

The data presented in table 2 depicts that the range of pre-test and post-test knowledge score was (5-20) and (15$37)$ respectively. Mean post-test knowledge score $(22.97 \pm 6.19)$ was higher than the mean pre-test knowledge score $(13.83 \pm 3.18)$. The data further reveals that the median of pre-test and post-test score were 13 and 21 respectively.

TABLE 2

Range, Mean, Median and Standard deviation of Pre-test and Post-test Knowledge Score of Nursing personnel

\begin{tabular}{lcccc} 
& & & N=30 \\
\hline $\begin{array}{l}\text { Knowledge } \\
\text { score }\end{array}$ & Range & Mean & Median & Standard deviation \\
\hline Pre-Test & $5-20$ & 13.83 & 13 & 3.18 \\
Post-Test & $15-37$ & 22.97 & 21 & 6.19 \\
\hline
\end{tabular}

Maximum score $=55$

The data presented in table 3 reveals that the mean post-test knowledge score of nursing personnel regarding concepts of thermal protection of neonates was 22.97 and the mean pre-test knowledge score was 13.83 with the mean difference of 9.14 . The calculated ' $t$ ' of 7.19 was found statistically significant at 0.05 level which represents that the mean difference between pre-test and post-test knowledge score was true difference and not by chance. 
TABLE 3

Mean, Mean Difference and Standard Error of Mean Difference and ' $t$ ' of Pre-test and Post-test Knowledge Score of Nursing personnel.

\begin{tabular}{llllll}
\multicolumn{1}{c}{ Knowledge score } & Mean & $\mathbf{M}_{\mathbf{D}}$ & $\mathbf{S D}_{\mathbf{D}}$ & $\mathbf{S E}_{\mathbf{M D}}$ & $\mathbf{N}=\mathbf{3 0}$ \\
\hline $\begin{array}{l}\text { Pre-Test } \\
\text { Post-Test }\end{array}$ & 13.83 & 9.14 & 3.01 & 1.27 & $7.19^{*}$ \\
\hline
\end{tabular}

't' (29) $=2.05$

*Significant $(\mathrm{p} \leq 0.05)$

The data presented in table 4 reveals that the range for pre-test skills score was (3-13) and post-test skills score was (9-22). The data also shows that the mean post-test skills score of nursing personnel regarding the thermal protection of neonates $(8.13 \pm 2.43)$ was higher than the mean pre-test skills score of nursing personnel(13.73 \pm 3.47$)$. The data further shows that the median pre-test skills score and post-test skills score were 8 and 14 respectively.

TABLE 4

Range, Mean, Median and Standard deviation of Pre-test and Post-test Skills Score of Nursing personnel

\begin{tabular}{lcccc}
\hline \multicolumn{1}{c}{ Skills score } & Range & Mean & Median & Standard deviation \\
\hline Pre-Test & $3-13$ & 8.13 & 8 & 2.43 \\
Post-Test & $9-22$ & 13.73 & 14 & 3.47 \\
\hline
\end{tabular}

Maximum score $=39$

Data presented in the table 5 reveals that the mean post-test skills score and mean pre-test skills score of nursing personnel regarding assessment of temperature was 13.73 and 8.13 respectively with mean difference of 5.60. The calculated ' $t$ ' of 7.27 was found to be statistically significant at 0.05 level which represents that the mean difference between pre-test and post-test skills score of nursing personnel was true difference and not by chance.

TABLE 5

Mean, Mean Difference and Standard Error of Mean Difference and 't' of Pre-test and Post-test Skills Score of Nursing personnel.

\begin{tabular}{lccccc} 
& & & & \\
\multicolumn{1}{c}{ Skills score } & Mean & $\mathbf{M}_{\mathbf{D}}$ & $\mathbf{S D}_{\mathbf{D}}$ & $\mathbf{S E}_{\mathbf{M D}}$ & 't' \\
\hline Pre-Test & 8.13 & 5.60 & 1.04 & 0.77 & $7.27^{*}$ \\
Post-Test & 13.73 & & &
\end{tabular}

$\mathrm{t}^{\prime}(29)=2.05$

*Significant $(\mathrm{p} \leq 0.05)$

The data presented in table 6 reveals that the co-efficient of correlation between pre-test knowledge score and pre-test skills score is 0.35 , suggesting a significant positive correlation between pre-test knowledge score and pre-test skills score. The calculated ' $r$ ' value $(0.35)$ between the pre-test knowledge score and pre-test skills score was significant at 0.05 level of significance which indicate that the co-relation is true co-relation and not by chance.

The data also reveals that the co-efficient of correlation between post-test knowledge score and post-test skills score was -0.05 suggesting a negligible negative correlation between post-test knowledge score and post-test skills score. The calculated ' $r$ ' value (-0.05) between the post-test knowledge score and assessment of temperature skills score is not significant at 0.05 level of significance.

TABLE 6

Correlation Between Knowledge Score and Skills Score of Nursing Personnel

\begin{tabular}{llcccc}
\hline \multirow{2}{*}{ TEST } & \multicolumn{2}{c}{ KNOWLEDGE SCORE } & \multicolumn{2}{c}{ SKILLS SCORE } & \multirow{2}{*}{ r } \\
\cline { 2 - 5 } & Mean & SD & Mean & SD & $0.35^{*}$ \\
Pre-test & 13.83 & 3.18 & 8.13 & 2.43 & -0.05 \\
Post-test & 22.97 & 6.19 & 13.73 & 3.47 & \\
\hline
\end{tabular}

$\mathrm{r}(28)=0.3061$

*Significant $(\mathrm{p} \leq 0.05)$

The table 7 depicts that the chi-square values showing that the knowledge of nursing personnel was not associated with age, marital status, professional qualification, overall years of experience, years of experience in paediatric and allied units, and exposure to any in-service education programme as chi-square values were not found statistically significant at 0.05 level of significance. 
TABLE 7

Chi-Square Value Showing Association between Gain in Post-Test Knowledge Score and Selected Variables

\begin{tabular}{|c|c|c|c|c|c|c|}
\hline \multirow{2}{*}{$\begin{array}{c}\text { S. } \\
\text { No. }\end{array}$} & \multirow[t]{2}{*}{ Sample Characteristics } & \multicolumn{2}{|c|}{ Knowledge Score } & \multirow[t]{2}{*}{$\overline{X^{2}}$} & \multirow[t]{2}{*}{ df } & \multirow{2}{*}{$\begin{array}{c}\mathrm{X}^{2} \\
\text { Table value }\end{array}$} \\
\hline & & Above Median & Below Median & & & \\
\hline 1 & Age: & & & & & \\
\hline 1.1 & $20-25$ years & $15(55.56 \%)$ & $12(44.44 \%)$ & $0.54^{\mathrm{NS}}$ & 1 & 3.81 \\
\hline 1.2 & 26-30 years & $01(33.33 \%)$ & $02(66.67 \%)$ & & & \\
\hline 3 & Marital status: & & & & & \\
\hline 3.1 & Unmarried & $15(55.56 \%)$ & $12(44.44 \%)$ & $0.54^{\mathrm{NS}}$ & 1 & 3.81 \\
\hline 3.2 & Married & $01(33.33 \%)$ & $02(66.67 \%)$ & & & \\
\hline 4 & Professional qualification: & & & & & \\
\hline 4.1 & GNM & $16(57.14 \%)$ & $12(42.86 \%)$ & & & \\
\hline 4.2 & $\begin{array}{l}\text { B. Sc. Nursing/ Post-basic B. Sc. } \\
\text { Nursing }\end{array}$ & $00(00.00 \%)$ & $02(100.00 \%)$ & $0.26^{\mathrm{NS}}$ & 3 & 7.81 \\
\hline 5 & Overall years of experience: & & & & & \\
\hline 5.1 & 3 months- 1 year & $12(52.17 \%)$ & $11(47.83 \%)$ & & & \\
\hline 5.2 & $>1-3$ years & $02(40.00 \%)$ & $03(60.00 \%)$ & $2.11^{\mathrm{NS}}$ & 2 & 5.99 \\
\hline 5.3 & $>3-5$ years & $02(100.00 \%)$ & $00(00.00 \%)$ & & & \\
\hline 6 & $\begin{array}{l}\text { Years of experience in the paediatric } \\
\text { and allied units: }\end{array}$ & & & & & \\
\hline 6.1 & 3 months-1 year & $12(46.15 \%)$ & $14(53.85 \%)$ & & & \\
\hline 6.2 & $>1-3$ years & $02(100.00 \%)$ & $00(00.00 \%)$ & $4.02^{\mathrm{NS}}$ & 2 & 5.99 \\
\hline 6.3 & $>3-5$ years & $02(100.00 \%)$ & $00(00.00 \%)$ & & & \\
\hline 7 & $\begin{array}{l}\text { Exposure to any in-service } \\
\text { education programme on thermal } \\
\text { protection of neonates: }\end{array}$ & & & & & \\
\hline 7.1 & Yes & $01(50.00 \%)$ & $01(50.00 \%)$ & $0.01^{\mathrm{NS}}$ & 1 & 3.81 \\
\hline 7.2 & No & $15(53.57 \%)$ & $13(46.43 \%)$ & & & \\
\hline
\end{tabular}

*Significant $(\mathrm{p} \leq 0.05)$

${ }^{\mathrm{N} / \mathrm{S}}$ Non-significant

The table 8 depicts that the chi-square values showing that the skills of nursing personnel were not associated with age, marital status, professional qualification, overall years of experience, years of experience in paediatric and allied units, and exposure to any in-service education programme as chi-square values were not found statistically significant at 0.05 level of significance.

TABLE 8

Chi-Square Value Showing Association between Gain in Post-Test Skills Score and Selected Variables

\begin{tabular}{|c|c|c|c|c|c|c|}
\hline \multirow{3}{*}{ S. No } & \multirow{3}{*}{ Sample Characteristics } & \multirow{2}{*}{\multicolumn{2}{|c|}{ Skills Score }} & \multirow{3}{*}{$\mathbf{X}^{2}$} & \multirow{3}{*}{ df } & $\mathbf{N}=$ \\
\hline & & & & & & \multirow{2}{*}{$\begin{array}{c}\mathrm{X}^{2} \\
\text { Table value }\end{array}$} \\
\hline & & Above Median & Below Median & & & \\
\hline 1 & Age: & & & \multirow{3}{*}{$2.54^{\mathrm{NS}}$} & \multirow{3}{*}{1} & \multirow{3}{*}{3.81} \\
\hline 1.1 & $20-25$ years & $15(55.56 \%)$ & $12(44.44 \%)$ & & & \\
\hline 1.2 & 26-30 years & $01(33.33 \%)$ & $02(66.67 \%)$ & & & \\
\hline 3 & Marital status: & & & \multirow{3}{*}{$2.54^{\mathrm{NS}}$} & \multirow{3}{*}{1} & \multirow{3}{*}{3.81} \\
\hline 3.1 & Unmarried & $15(55.56 \%)$ & $12(44.44 \%)$ & & & \\
\hline 3.2 & Married & $01(33.33 \%)$ & $02(66.67 \%)$ & & & \\
\hline 4 & Professional qualification: & & & \multirow{3}{*}{$1.46^{\mathrm{NS}}$} & \multirow{3}{*}{3} & \multirow{3}{*}{7.81} \\
\hline 4.1 & GNM & $16(57.14 \%)$ & $12(42.86 \%)$ & & & \\
\hline 4.2 & $\begin{array}{l}\text { B. Sc. Nursing/ Post-basic B. Sc. } \\
\text { Nursing }\end{array}$ & $00(00.00 \%)$ & $02(100.00 \%)$ & & & \\
\hline 5 & Overall years of experience: & & & \multirow{4}{*}{$2.10^{\mathrm{NS}}$} & \multirow{4}{*}{2} & \multirow{4}{*}{5.99} \\
\hline 5.1 & 3 months-1 year & $12(52.17 \%)$ & $11(47.83 \%)$ & & & \\
\hline 5.2 & $>1-3$ years & $02(40.00 \%)$ & $03(60.00 \%)$ & & & \\
\hline 5.3 & $>3-5$ years & $02(100.00 \%)$ & $00(00.00 \%)$ & & & \\
\hline 6 & $\begin{array}{l}\text { Years of experience in the paediatric } \\
\text { and allied units: }\end{array}$ & & & & & \\
\hline 6.1 & 3 months-1 year & $12(46.15 \%)$ & $14(53.85 \%)$ & \multirow{3}{*}{$3.17^{\mathrm{NS}}$} & \multirow{3}{*}{2} & \multirow{3}{*}{5.99} \\
\hline 6.2 & $>1-3$ years & $02(100.00 \%)$ & $00(00.00 \%)$ & & & \\
\hline 6.3 & $>3-5$ years & $02(100.00 \%)$ & $00(00.00 \%)$ & & & \\
\hline 7 & $\begin{array}{l}\text { Exposure to any in-service education } \\
\text { programme on thermal protection of } \\
\text { neonates: }\end{array}$ & & & \multirow{3}{*}{$2.79^{\mathrm{NS}}$} & \multirow{3}{*}{1} & \multirow{3}{*}{3.81} \\
\hline 7.1 & Yes & $01(50.00 \%)$ & $01(50.00 \%)$ & & & \\
\hline 7.2 & No & $15(53.57 \%)$ & $13(46.43 \%)$ & & & \\
\hline
\end{tabular}

*Significant $(\mathrm{p} \leq 0.05)$

${ }^{\mathrm{N} / \mathrm{S}}$ Non-significant 
Thus, the video teaching programme was effective in enhancing the knowledge as well as the skills of nursing personnel regarding the concept of thermal protection of neonates.

\section{Discussion}

The present study findings indicate that nursing personnel had below average knowledge regarding the concept of thermal protection of neonates. These findings are consistent with the findings of the study conducted by Choudhary SP et. al (2000) ${ }^{[\mathrm{x}]}$ on knowledge about neonatal hypothermia among medical and paramedical staff which show the lack of knowledge among nursing personnel regarding various aspects of neonatal hypothermia.

The results of present study show that mean post-test knowledge score of nursing personnel regarding the concept of thermal protection of neonates was higher than the mean pre-test knowledge score. These findings coincide with the findings of the study conducted by Laxmi (2005) ${ }^{[\mathrm{xi}]}$ and Dutta Parul (1996) ${ }^{[\mathrm{xii}]}$ to evaluate the effectiveness of a planned teaching programme on thermoregulation of neonates in terms of knowledge and practice of nursing personnel which showed a significant increase in the post-test knowledge and practice scores. The study findings also coincide with the findings of the study conducted by Begum Mumtaz (2009) $^{[\text {xiii] }}$ to evaluate the effectiveness of competency based teaching programme on prevention of neonatal hypothermia in terms of knowledge, attitude and practices of nurses which showed increase in knowledge, improvement of attitude and practices.

As India is a developing country with limited resources and high neonatal mortality rate, the increase in knowledge will help the nursing personnel to provide effective care and thermal neutral environment to neonates thereby reducing the neonatal mortality and morbidity. Efforts should be made to sensitize and educate all levels of staff dealing with neonates, and low-reading thermometers should be part of the essential kit in the unit.

Nursing personnel are the only persons who deal with the neonates immediately after birth. Also, today's students are the future nurses who will be working at bed side. Though the thermal protection of neonates is there as a topic in the curriculum still the nursing personnel don't have sufficient knowledge regarding it. So, the teachers should emphasize on this topic. Use of interactive teaching methods such as demonstration, documentary, role play, use of audio-visual tapes, slide shows etc. add an important dimension to the presentation thereby increasing the understanding and retention level and help the learner to use their visual capacity.

The study was confined to small group (30) of nursing personnel working in paediatric and allied units regarding the concept of thermal protection of neonates in selected hospitals of Ambala, Haryana. This limits the generalization of the findings. So, the study can be replicated on a larger sample of nursing personnel for wider generalization of the findings and a study can be carried out by using true experimental design or other teaching strategies like information booklet, SIM, manual, computer assisted instruction, or competency based teaching etc.

\section{REFERENCES}

[1]. Marlo DR, Barbara [2005].A textbook of paediatric nursing. Saurabi printer private limited

[2]. Vobra S et al. Effect of polyethylene occlusive skin wrapping on heat loss in very low birth weight infant at delivery: a randomized trial. Journal of pediatrics, 1999, 134:547-51.

[3]. Kumar V, Shearer JC,, Kumar A, Darmstadt GL: neonatal hypothermia in low resource setting: a review; J Perinatal 2009, $29(6)$ : 401-412.

[4]. World Health Organization: Thermal Protection of the Newborn: A Practice Guide. Geneva: World Health Organization; 1997.

[5]. Mullany LC, Katz J, Khatry SK, LeClerq SC, Darmstadt GL, Tielsch JM: Risk of mortality associated with neonatal hypothermia in Southern Nepal. Arch PediatrAdolesc Med 2010, 164 (7): 650-656.

[6]. Talea Miller.Health. Newborn Mortality Rates August 31, 2011 http://www.pbs.org/newshour/rundown/2011/08/slideshow-the-best-andworst-countries-for-newborn-safety.html

[7]. WHO, 2007. Neonatal and perinatal mortality: Country, regional and global estimates. Available from: http://whqlibdoc.who.int/publications/2007/9789241596145 eng.pdf.

[8]. Family welfare statistics in India 2011. pdf:xiii-xiv.

[9]. Manji KP, Kisenge R. Neonatal hypothermia on admission to a special care unit in Dar-es-Salam, Tanzania: a cause for concern. Central African journal of medicine, 2003, 49:23-7.

[10]. Choudhary SP etal. Knowledge, attitude and practices about neonatal hypothermia among medical and paramedical staff. 2000;67(7):491-6.

[11]. Laxmi. A study to evaluate the effectiveness of planned teaching programme on the thermoregulation of neonates in terms of knowledge and practices of nursing personnel working in labour room of selected hospitals and maternity homes of Delhi. Unpublished Master of nursing dissertation.Delhi University. 2005

[12]. DuttaParul. A study to evaluate the effectiveness of a planned teaching programme on thermoregulation of neonates in terms of knowledge and practice of nursing personnel working in labour room and neonatal care unit in selected hospitals of West Bengal. Unpublished master dissertation.Delhi University. 1996.

[13]. Begum MamtazMs. Effectiveness of competency based teaching programme on prevention of neonatal hypothermia. Asian journal of cardiovascular nursing.2009 Jan 17; 1:12-16. 